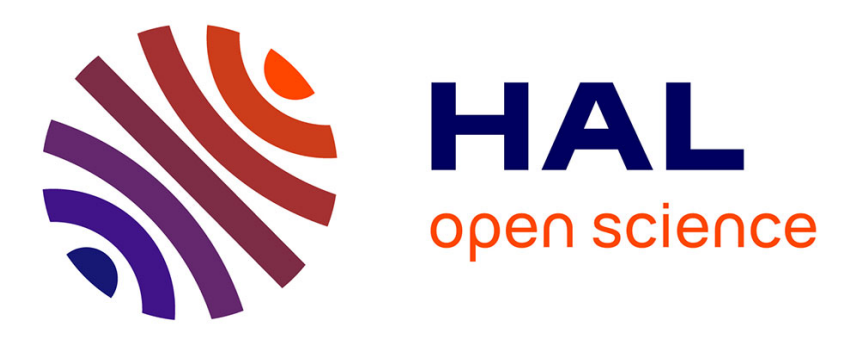

\title{
Three-level Inverter Fault Detection and Diagnosis Using Current-based Statistical Analysis
}

Mehdi Baghli, Claude Delpha, Demba Diallo, Abdelhamid Hallouche

\section{To cite this version:}

Mehdi Baghli, Claude Delpha, Demba Diallo, Abdelhamid Hallouche. Three-level Inverter Fault Detection and Diagnosis Using Current-based Statistical Analysis. Prognostics and Systems Health Management Conference (PHM-Chongqing 2018), Oct 2018, Chongqing, China. 10.1109/phmchongqing.2018.00123 . hal-01895228

\section{HAL Id: hal-01895228 \\ https://hal-centralesupelec.archives-ouvertes.fr/hal-01895228}

Submitted on 12 Mar 2020

HAL is a multi-disciplinary open access archive for the deposit and dissemination of scientific research documents, whether they are published or not. The documents may come from teaching and research institutions in France or abroad, or from public or private research centers.
L'archive ouverte pluridisciplinaire HAL, est destinée au dépôt et à la diffusion de documents scientifiques de niveau recherche, publiés ou non, émanant des établissements d'enseignement et de recherche français ou étrangers, des laboratoires publics ou privés. 


\title{
Three-level Inverter Fault Detection and Diagnosis Using Current-based Statistical Analysis
}

\author{
M. Baghli ${ }^{1,3}$, C. Delpha ${ }^{2}$, D. Diallo ${ }^{3,4}$, A. Hallouche ${ }^{1}$ \\ ${ }^{1}$ Laboratoire IRECOM, Univ. Djillali Liabès, Sidi Bel Abbes, Algérie \\ ${ }^{2}$ Laboratoire des Signaux et Systèmes, UMR 8506, CNRS, CentraleSupelec, Univ. Paris Sud, Université Paris Saclay, \\ ${ }^{3}$ Laboratoire GeePs, UMR 8507, CNRS, CentraleSupelec, Univ. Paris Sud, Université Paris Saclay, \\ Sorbonne Université \\ ${ }^{4}$ Shanghai Maritime University, Department of Electrical Automation, Shanghai, China
}

\begin{abstract}
This paper deals with open switch Fault Detection and Diagnosis (FDD) in three-level Neutral Point Clamped (NPC) inverter for electrical drives. The approach is based on the already available phase current measurements. The fault features that are evaluated in the time domain are the first four statistical moments. Three methods of FDD have been evaluated. The first one analyses the time domain evolution of the fault features. With this method, the fault is detected with a probability of detection higher than $80 \%$ when the operating speed is higher than a tier of the nominal speed and the SNR $\geq$ 40dB. However, the performances are degraded for low speed and for lower SNR. To improve the performances, we use the Cumulative Sum (CUSUM) algorithm designed for mean and variance variations. The optimality has been verified with the Kolmogorov-Smirnov test of the selected features Probability Density Functions (PDF). The fault is detected efficiently with both CUSUM indicators with almost $100 \%$ of detection probability even for the smallest considered fault duration of $100 \mu \mathrm{s}$.
\end{abstract}

Keywords - Three-level Neutral Point Clamped (NPC) inverter; Open Switch Fault (OSF); Intermittent faults effect; Fault Detection and Diagnosis (FDD); Cumulated Sum (CUSUM) analysis

\section{INTRODUCTION}

Electrical drives are widely used in a variety of applications industrial, manufacturing, and transportation applications. Their reliability is closely related to the robustness of each component. In particular, the voltage source inverters are key components of these electrical drives.

During the last decades, multilevel inverters have become more and more popular because of the improvement of the output voltage quality, the reduction of the electrical constraints on the power switches and the reduction of the switching frequency. Indeed, they generate less electromagnetic perturbations and therefore the size and the cost of the main filter can be reduced [1]. However, the main drawbacks are the higher number of components (compared to the classical 2-level inverter) and a more complex control [2]. In [1] the authors have made a comparison between four topologies of inverters in terms of semiconductor and capacitors losses: the conventional structure, an interleaved two-level inverter; the Neutral Point Clamped (NPC) structure and the cascaded three-level H-bridge. The NPC inverter has proved to be the most efficient.

In this paper, the three-level NPC inverter is chosen because it has lower inverter losses and lower stress on the power switches at higher switching frequencies compared to a two-level inverter for electric vehicle applications [3].

It has been estimated that about $38 \%$ of the faults in variable-speed $\mathrm{AC}$ drives in industry are due to failures of power devices [4]. We can classify the faults in three groups: abrupt, gradual and intermittent faults. The impact of abrupt faults on electrical machine has been more often treated [5] than intermittent ones.

In this work, we are interested in the intermittent openswitch faults. Even they do not induce so critical modifications (as it can be seen in Fig.1 on the inverter output current $I s$ or the drive electromagnetic torque $T e$ ), the frequent occurrence of such faults will generate a cumulative stress that can lead to failure of the inverter.

Recently, several methods have been developed for fault detection in power converters. The methods based on Park's vector $[6,7]$ unfortunately require complex pattern recognition algorithms. The methods based on voltages require undesirable extra hardware [8]. We propose in the following to use the already available current measurements.

This paper is organized as follows. Section I gives the introduction and the existing literature background and section II introduces the statistical moments used as fault features for Fault Detection and Diagnosis (FDD). In Section III, the FDD method based on CUSUM test is detailed and the overall performances are discussed. Finally, conclusions are given in Section IV. 


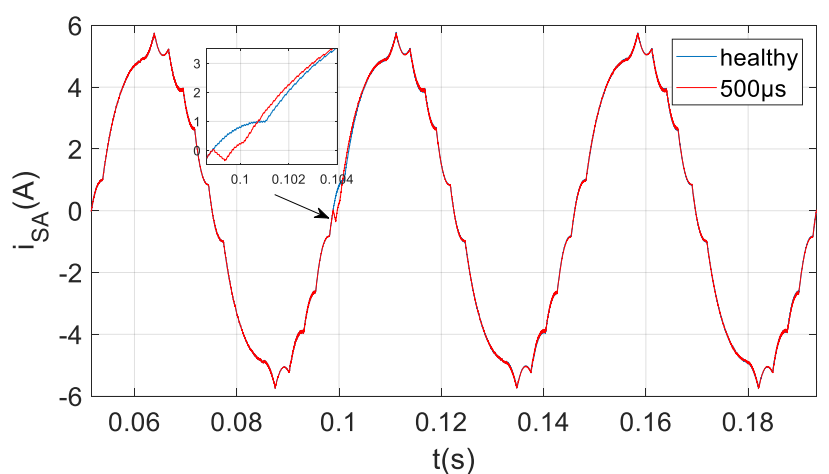

(a) Current waveforms in healthy and faulty cases

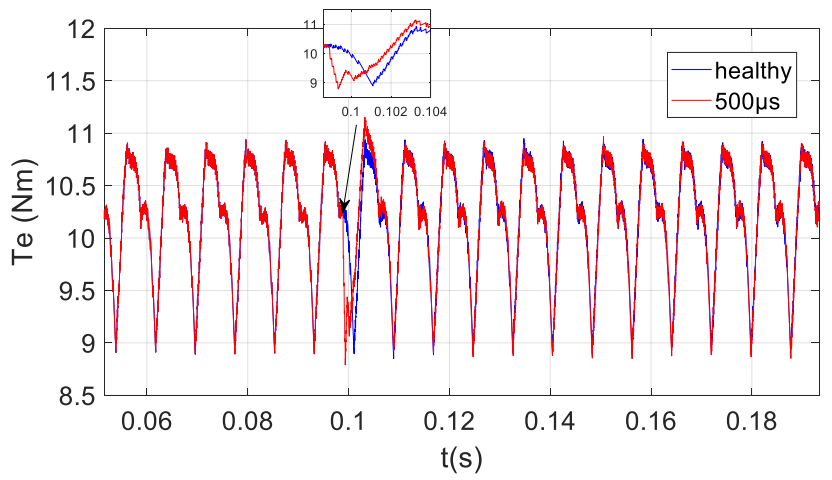

(b) Electromagnetic torque in healthy and faulty cases

Fig. 1. Intermittent $500 \mu$ s fault impact on current and torque

\section{FAULT DETECTION USING STATISTICAL MOMENTS}

\section{A. System description}

The three-level NPC inverter is one of the famous multilevel configurations explored in the literature [9-11]. Fig. 2 shows the topology of a three-level NPC inverter. The inverter has three legs (A, B and $\mathrm{C}$ ) each one has four active switches with anti-parallel diodes. The DC bus has 2 capacitors, thus providing the middle point "O".

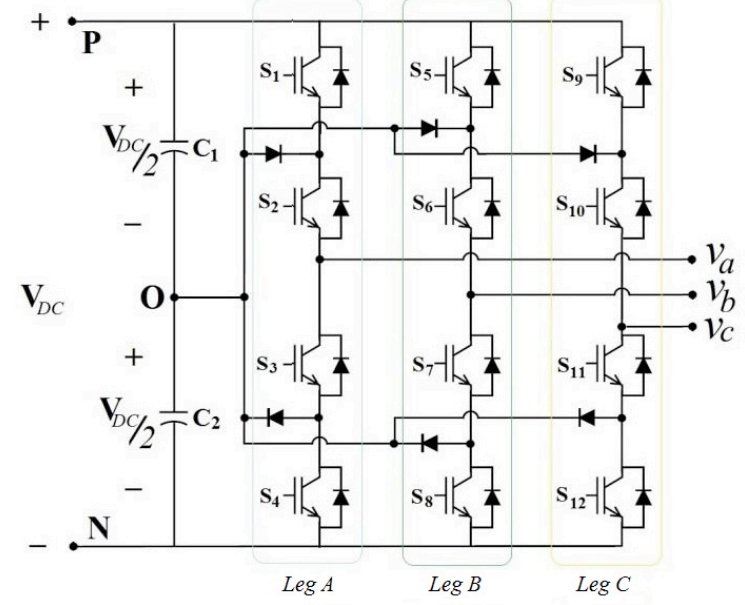

Fig. 2. Schematic representation of a three-level NPC inverter
This work is focused on the Open Switch Fault (OSF) on the first switch $\mathrm{S}_{1}$ of leg A (Fig. 2.).

With no loss of generality, for this work, the considered NPC inverter is switched at $10 \mathrm{kHz}$ with a sampling frequency of $100 \mathrm{kHz}$. This inverter feed an asynchronous machine drive in a speed controlled loop (Fig. 3).

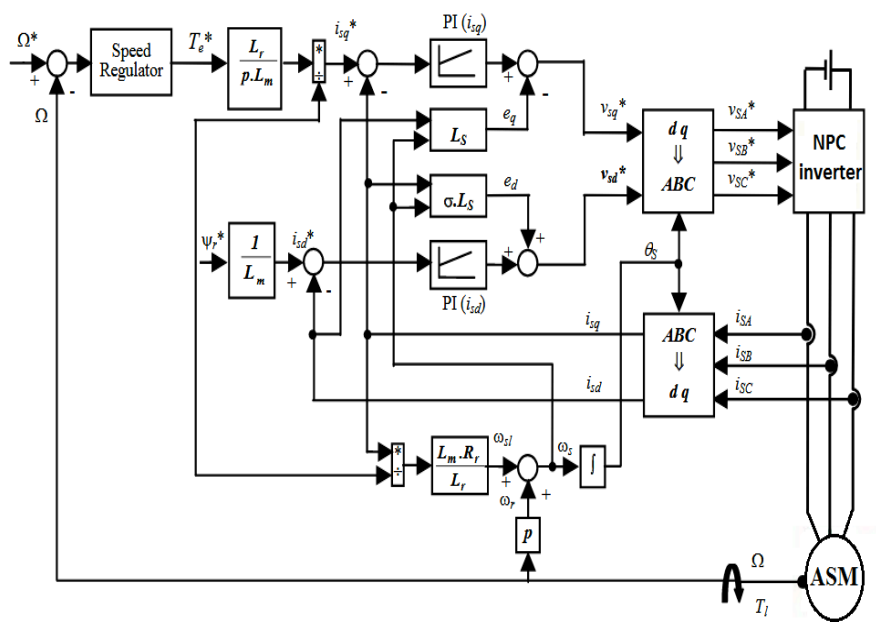

Fig. 3. Block diagram of indirect field oriented control scheme

The main characteristics of this machine drive are summarized in the Table 1.

TABLE I. ASYNCHRONOUS MACHINE MAIN CHARACTERISTICS

\begin{tabular}{|c|c|c|}
\hline Charateristic & Value & Unit \\
\hline Nominal voltage & $U_{n}=220 / 380$ & Volts \\
\hline Nominal speed & $N_{n}=1420$ & $\mathrm{rpm}$ \\
\hline Nominal power & $P_{n}=1.5$ & $\mathrm{~kW}$ \\
\hline Rated torque & $T_{n}=10$ & N.m \\
\hline Nominal frequency & $f=50$ & Hertz \\
\hline Number of poles & $p=2$ & \\
\hline Stator resistance & $R s=4.85$ & $\Omega$ \\
\hline Rotor self-resistance & $R r=3.805$ & $\Omega$ \\
\hline Stator self-inductance & $L s=0.274$ & Henry \\
\hline Rotor inductance & $L r=0.274$ & Henry \\
\hline Mutual inductance (stator-rotor) & $L m=0.258$ & Henry \\
\hline Moment of inertia & $J=0.031$ & kg.m ${ }^{2}$ \\
\hline
\end{tabular}

The output currents feeding the asynchronous machine drive are observed and considered for the FDD study.

The classical field oriented indirect method is adopted as displayed in Fig. 3 [12].

\section{B. Application of statistical moments on current measurement}

The first four statistical moments of the current flowing in phase A are computed. If we denote the current as a variable 
$X=\left(x_{1}, \ldots, x_{j}, \ldots, x_{N}\right)$ composed of $\mathrm{N}$ samples, the first four statistical moments are defined below as:

- $\mu=\frac{1}{N} \sum_{1}^{N} x_{j}$ is the mean value; it represents the center of the signal distribution,

- $\sigma^{2}=\frac{1}{N} \sum_{1}^{N}\left(x_{j}-\mu\right)^{2}$ denotes the variance and measures the dispersion within the signal distribution,

- $S k w=\frac{1}{N} \sum_{1}^{N}\left(\frac{x_{j}-\mu}{\sigma}\right)^{3}$ is the Skewness value that measures the dissymmetry of the signal distribution,

- $K u r=\frac{1}{N} \sum_{1}^{N}\left(\frac{x_{j}-\mu}{\sigma}\right)^{4}$ is the Kurtosis value that measures the flatness of the signal distribution.

The faults can be classified according to their time durations. In the following ten cases are under study from $100 \mu \mathrm{s}$ to $1 \mathrm{~ms}$ with a $100 \mu \mathrm{s}$ step $(100 \mu \mathrm{s}, 200 \mu \mathrm{s}, \ldots, 900 \mu \mathrm{s}$, $1 \mathrm{~ms})$. The smallest fault duration value is related to the switching frequency set at $10 \mathrm{kHz}$.

The analyses of the ten faulty cases are done for:

- Three rotating speeds (20, 40 and $60 \mathrm{rad} / \mathrm{s})$ according to European Urban Driving Cycle (EUDC).

- Three different loads (no load, $50 \%$ and $100 \%$ of the rated torque).

In the following, only a selected part of the obtained results will be presented. Those chosen best highlights the global behaviour with the fault occurrence and the detection performances for the different speed and load conditions.

Fig. 4 shows the evolution of the first four statistical moments for two faulty OSF $(100 \mu$ s and $500 \mu$ s of duration) at $60 \mathrm{rad} / \mathrm{s}$ for the rated load. The first 500 realisations correspond to the healthy case and the last 500 ones to the faulty case for a noise level such as $\mathrm{SNR}=40 \mathrm{~dB}$.

From Fig. 4, we can draw the following remarks:

- For both faults, the skewness and the kurtosis exhibit significant variations between healthy and faulty cases,

- For both faults, the variance has a less significant variation,

- For both faults, the mean value is obviously not a reliable fault indicator.
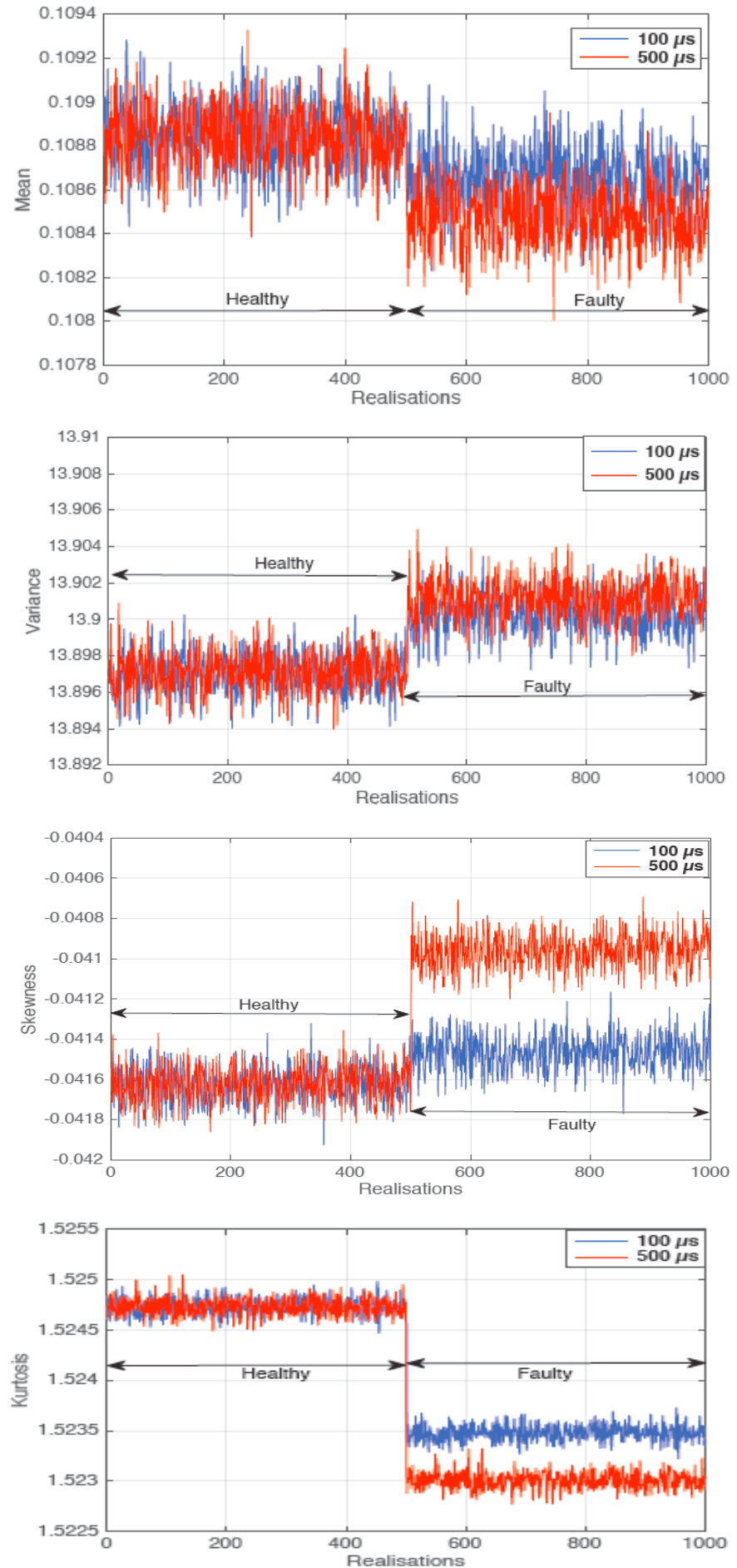

Fig. 4. Statistical moments for the two faults with $\mathrm{SNR}=40 \mathrm{~dB}$

For the same fault durations, we have evaluated only the skewness and the kurtosis with lower SNR (35, 30, 25 and 20 $\mathrm{dB})$ meaning a higher level of noise in the measurements. The results are displayed in Fig. 5 only for $20 \mathrm{~dB}$ (most severe noise conditions here) for the same operating points. 
From Fig. 5, we can notice that the kurtosis exhibits a small variation between the healthy and faulty cases but the performances of the fault detection will be very low (in terms of fault probability of detection and false alarms). The other features are almost constant for both cases (healthy and faulty). We can conclude that the fault detection is almost impossible with these four features in these extreme conditions of noise (low SNR).
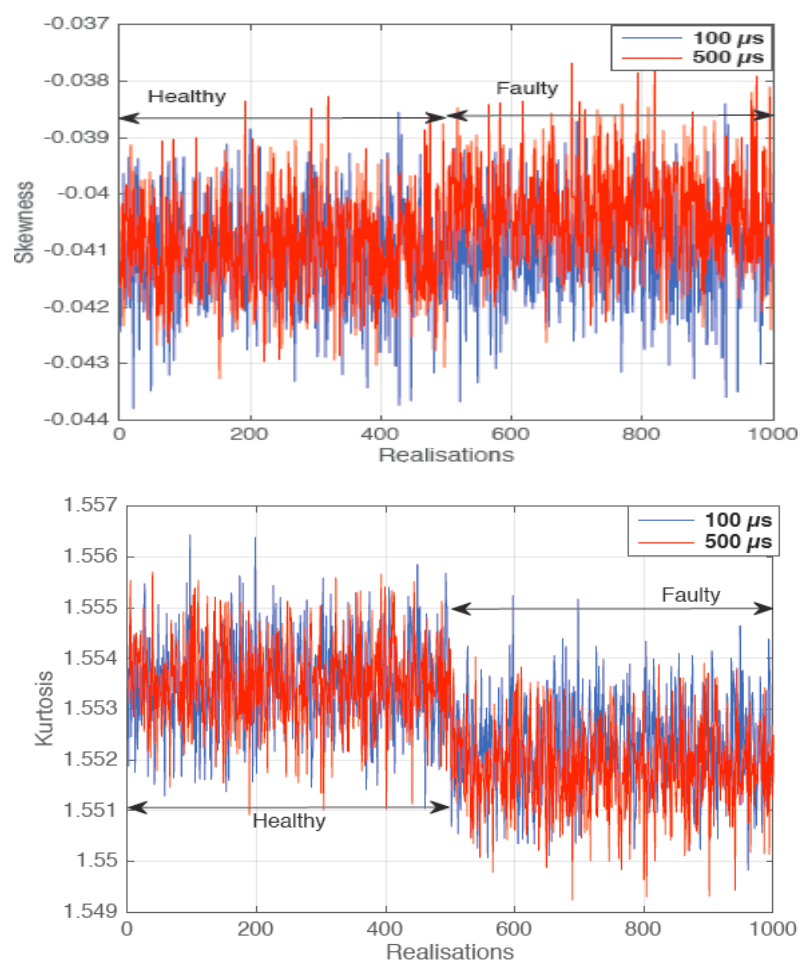

Fig. 5. Statistical moments for the two faults with $\mathrm{SNR}=20 \mathrm{~dB}$

The probability of detection $\left(\mathrm{P}_{\mathrm{D}}\right)$ and the probability of false alarm $\left(\mathrm{P}_{\mathrm{FA}}\right)$ are calculated as follows:

$$
P_{D}=\frac{T P}{T P+F N} \quad \text { and } \quad P_{F A}=\frac{T N}{T N+F P}
$$

Where TP is true positive and represents the number of realisations for faulty cases (501 to 1000) that are higher or equal than the detection threshold, while $\mathrm{FN}$ is false negative and is calculated by $\mathrm{FN}=$ (number of realizations)-TP. The FP is false positive and it represents the number of realisations for healthy cases ( 1 to 500) that are higher or equal than the threshold and true negative $\mathrm{TN}=$ (number of realizations)-FP.

The performances regarding the SNR evolution is computed for the two considered features. The Receiver Operating Characteristics (ROC) curve is then computed and presented in the Fig. 6 for the smallest fault occurrence $(100 \mu \mathrm{s})$, with speed $60 \mathrm{rd} / \mathrm{s}$ and torque $10 \mathrm{Nm}$.
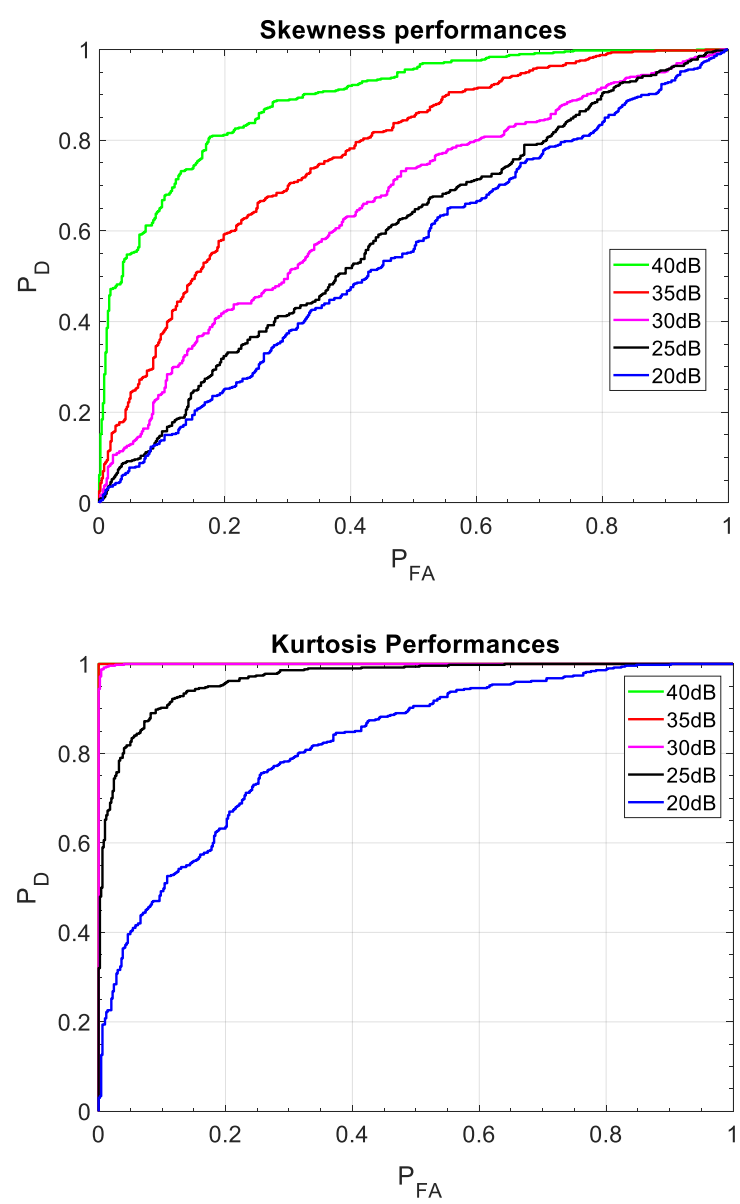

Fig. 6. Performances of Skewness and Kurtosis for several noise conditions $(60 \mathrm{rd} / \mathrm{s})$

With these ROC curves (Fig. 6) we can derive an optimal fault detection threshold for these features leading to the best trade-off value between $\mathrm{P}_{\mathrm{D}}$ and $\mathrm{P}_{\mathrm{FA}}$. It is clear that while the noise conditions became more severe (SNR decrease), the optimal fault detection will lead to $\mathrm{P}_{\mathrm{D}}<0.7$ and $\mathrm{PFA}>0.3$. It means that the fault detection efficiency using these selected features in severe noise conditions will be reduced.

Nevertheless, in these conditions, the feature allowing to obtain the best performances is the Kurtosis even for the smallest fault occurrence (Fig. 6).

When the rotational speed is reduced, these performances will decrease. Fig. 7 displays the performances for the Kurtosis for the same load (torque $10 \mathrm{Nm}$ ) and noise (SNR=20dB) conditions. This confirms that the detection performances will be decreased along with the machine drive speed. For $20 \mathrm{rd} / \mathrm{s}$, the optimal threshold will lead to $\mathrm{P}_{\mathrm{D}}=0.56$ and $\mathrm{P}_{\mathrm{FA}}=0.44$. This is must be improved for an efficient FDD process. Using the Skewness, the results are quite similar $\left(\mathrm{P}_{\mathrm{D}}=0.63\right.$ and $\left.\mathrm{P}_{\mathrm{FA}}=0.4\right)$. 


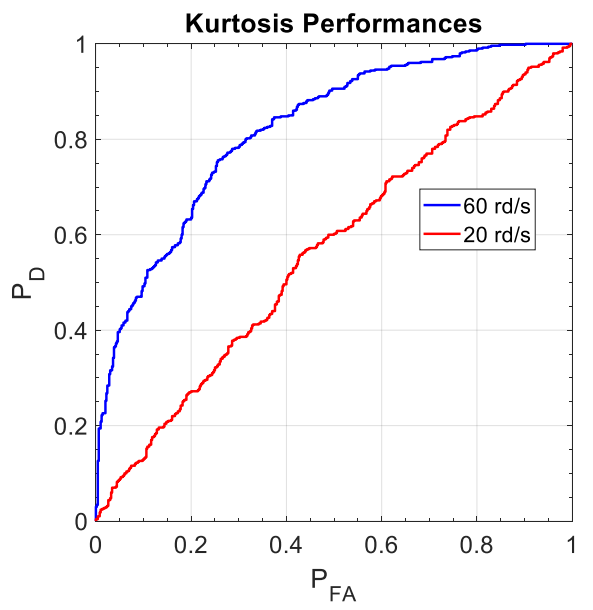

Fig. 7. Performances of Kurtosis in different speed conditions ( $\mathrm{SNR}=20 \mathrm{~dB})$

Hence, it is necessary to improve the FDD with these features for these particular high noise and low speed conditions. For this purpose, in the next section we propose to apply the CUSUM algorithm to these statistical moments. This methodology is described below.

\section{DeteCtion USING CUSUM ALGORITHM}

The CUmulative SUM (CUSUM) algorithm is widely used to detect changes in the mean value or variance for an independent Gaussian sequence; it is based on log-likelihood ratio. The theoretical background of CUSUM can be found in [13-15].

\section{A. Probability Density Function (PDF)}

Most often, a PDF is used to specify the probability of the random variable falling within a particular range of values. Its integral across an interval gives the probability that the value of the variable lies within the same interval.

In order to take benefit from the optimality of the CUSUM algorithm, the Probability Density Function (PDF) of the variables under study should be Gaussian. This is checked with the Kolmogorov-Smirnov test evaluated on the PDFs displayed in Fig. 8. This test is a nonparametric criteria used to evaluate the difference between two standard normal distributions (SND), and also to compare a reference distribution with SND.

Fig. 8 displays the PDFs of the 4 statistical moments in healthy and faulty conditions $(100,200$ and $500 \mu$ s OSF duration) at a speed of $20 \mathrm{rad} / \mathrm{s}$ for the rated load with $\mathrm{SNR}=20 \mathrm{~dB}$.

The results of the application of the Kolmogorov-Smirnov test on the PDFs for all the operating conditions and for the considered SNR (20 to $40 \mathrm{~dB}$ ) confirms that the features PDF can be considered as Gaussian. The CUSUM can be the applied optimally.
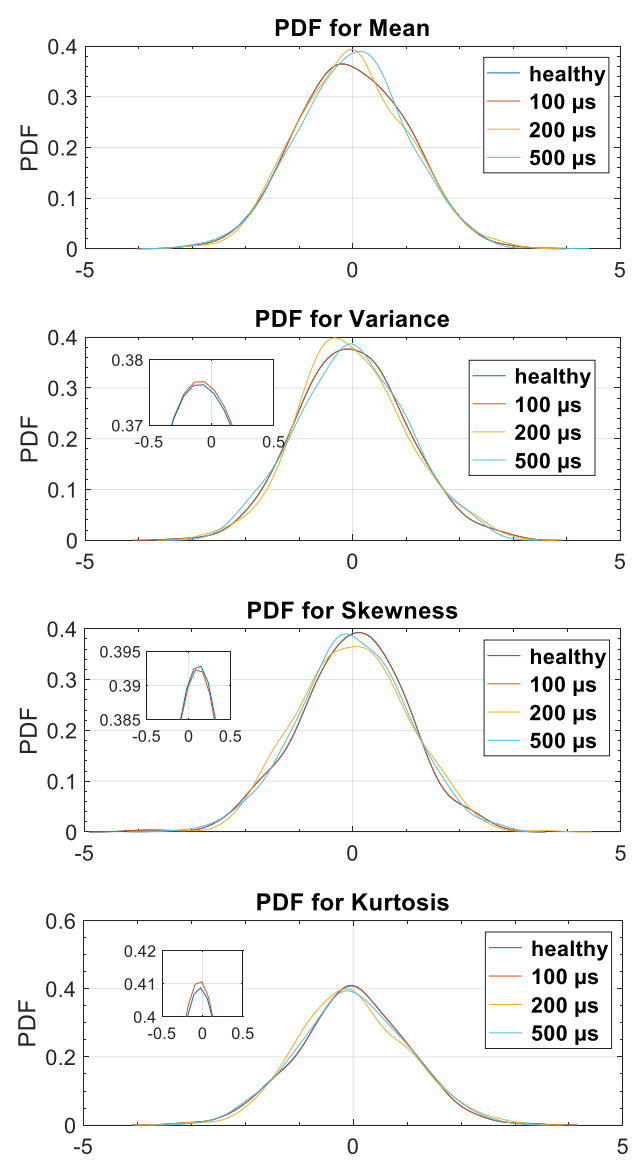

Fig. 8. PDF of the first four moments with $\mathrm{SNR}=20 \mathrm{~dB}(20 \mathrm{rd} / \mathrm{s})$

\section{B. CUSUM}

As defined earlier, the CUSUM is used to detect small changes. It is hereafter applied on each of the 4 statistical moments $\left(\mu, \sigma^{2}, S k w, K u r\right)[14,15]$. The CUSUM function denoted $S_{N}$ is optimally derived as the sum of the sufficient statistics $s_{k}$ such as:

$$
S_{N}=\sum_{k=1}^{N} s_{k}
$$

Where $\mathrm{N}$ is the number of realisations and $s_{k}$ can be considered in the case of mean changes ( 8 ) or variance changes ( $\left.S_{\infty}\right)$ for the first four statistical moments as defined below:

$$
\begin{aligned}
& s_{k_{\mu}}=\left(\frac{\mu_{f}-\mu_{h}}{\sigma^{2}}\right) \times\left(x_{k}-\frac{\mu_{f}+\mu_{h}}{2}\right) \\
& s_{k_{\sigma}}=\ln \frac{\sigma_{h}}{\sigma_{f}}+\left(\frac{1}{\sigma_{h}^{2}}-\frac{1}{\sigma_{f}^{2}}\right) \times\left(x_{k}-\mu_{h}\right)
\end{aligned}
$$

Where $\mu_{h}$ and $\mu_{f}$ are respectively the mean values in the healthy and faulty conditions, $\sigma_{h}$ and $\sigma_{f}$ are respectively the standard deviation values in healthy and faulty conditions, and $x_{k}$ stands for the statistical moment under consideration for the $k^{\text {th }}$ observation over N. While computing the CUSUM $S_{N}$, we can 
then set a threshold $T_{h}$ at 0.99 of its maximum value in healthy case $S_{\max }$. If the CUSUM value is higher than $T_{h}$ then it means that a faulty behaviour has been detected.

Fig. 9 and Fig. 10 show respectively the application of $s_{k_{\mu}}$ and $s_{k_{\sigma}}$ on the samples for the skewness with $\mathrm{SNR}=20 \mathrm{~dB}$ at $20 \mathrm{rad} / \mathrm{s}$ for the rated load. The first 500 samples represent the healthy condition and the 500 others the faulty condition.

The fault is detected efficiently with both indicators: only 20 faulty realizations needed for CUSUM mean and 23 faulty realizations for CUSUM variance. There is no missed detection for CUSUM variance and only one for CUSUM mean.
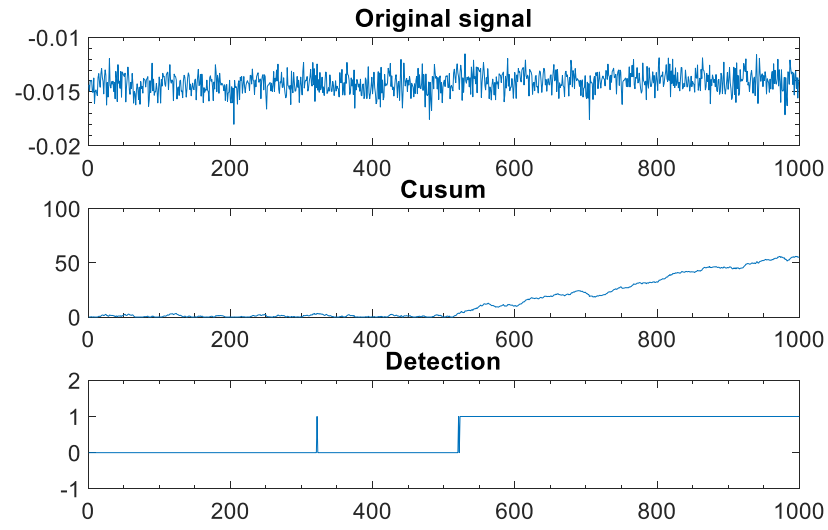

Fig. 9. $100 \mu$ s Fault Detection results with CUSUM Mean with skewness
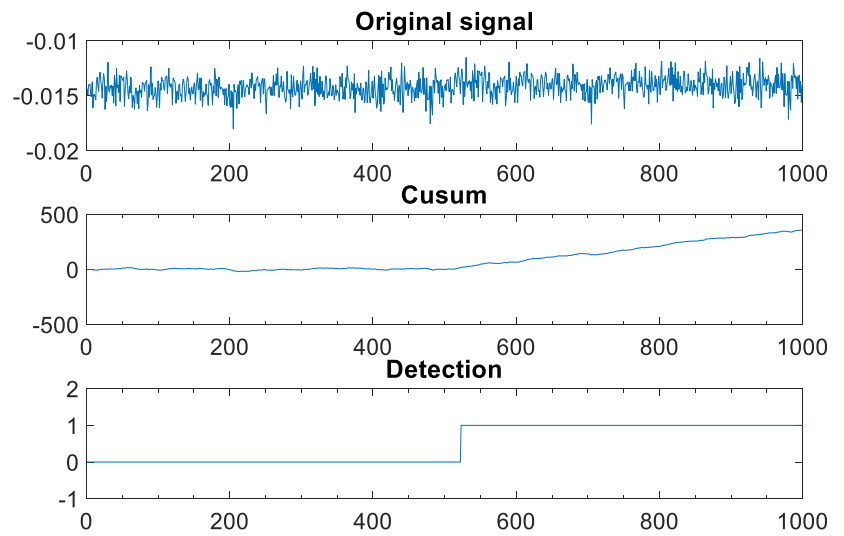

Fig. 10. $100 \mu$ s Fault Detection results with CUSUM Variance with skewness

The same types of good results are obtained using the CUSUM for the Kurtosis realisations.

\section{CONCLUSION}

This paper deals with open switch fault detection and diagnosis in three-level NPC inverter for electrical drives. Two statistical techniques have been proposed for the FDD methodology and then evaluated. At first, a solution based on the extraction and analysis of the first four statistical moments of the current flowing in the windings of the machine is proposed. With this method, the fault is detected with a probability of detection higher than $80 \%$ when the rotating speed is higher than the tier of the nominal speed. However, the performances are degraded at lower speed and for lower SNR (high noise levels). Then at second we have used the CUSUM for mean and variance variations to improve the detection. Better performances are obtained for the detection of the incipient faults in low speed and high noisy conditions.

\section{REFERENCES}

[1] S. M. Sharkh, M. A. Abusara, G. I. Orfanoudakis, and B. Hussain. "Power Electronic Converters For Microgrids," IEEE Wiley, pp. 1-72, 2014.

[2] M. Ikonen, O. Laakkonen, and M. Kettunen, "Two-Level and ThreeLevel Converter Comparison in Wind Power Application," www.elkraft.ntnu.no/smola2005/Topics/15.pdf, Finland, (accessed 23 October 2013).

[3] A. Choudhury, "Three-level neutral point clamped traction inverter drive for electric vehicles," thesis in electrical and computer engeneering, supervised by Dr. P. Pillay, Montreal, Concordia University, April 2015.

[4] R. Errabelli and P. Mutschler, "Fault-tolerant voltage source inverter for permanent magnet drives," IEEE Trans. Power Electronics, vol. 27, n², pp. 500-508, February 2012.

[5] S. E. Varghese and Reema N, "Effects of Switching Faults on Induction Motor Drive System," International research journal of engineering and technology (IRJET), vol. 3, n5, pp. 607-611, May 2016.

[6] K. Rothenhagen and F. W. Fuchs, "Performance of diagnosis methods for IGBT open circuit faults in voltage source active rectifiers," IEEE PESC proc, pp.4348-4354, 2004.

[7] A. M. S. Mendes, A. J. M. Cardoso and E. S. Saraiva, "Voltage source inverter fault diagnosis in variable speed $\mathrm{AC}$ drives, by the average current Park's vector approach," IEEE IEMDC Proc, pp.704-706, 1999.

[8] K. S. Kim, M. J. Jang, N. T. Hai, N. B. Lai, J. H. Song and K. H. Kim, "Open-switch fault detection and faulty switch identification of PWM inverter in PMSM drives using DOB based voltage information," International journal of applied engineering research, Research India Publications, vol. 11, n², pp. 1494-1502, 2016.

[9] D. W. Feng, B. Wu, et al., "Space Vector Modulation for Neutral Point Clamped Multilevel Inverter with Even Order Harmonic Elimination", Canadian Conference on Electrical and Computer Engineering (CCECE), pp. 1471-1475, 2004.

[10] B. Wu, "High Power Converters and AC Drives", IEEE Press/Wiley ISBN: 0-4717-3171- 4 Nov. 2005.

[11] J. H. Seo, C. H. Choi, et al., "A New Simplified Space Vector PWM Method for Three-Level Inverters", IEEE Transactions on Power Electronics, Vol. 16, No. 4, pp. 545-555,2001.

[12] H. Athar, I. B. Aamer, Y. Abdul Rehman, M. Ghulam, and A. Qadeer, "Sliding mode-based observer design for field-oriented control of induction machine drive for applications in hybrid electric vehicles," IEEE Proceedings of the 33rd Chinese Control Conference, Nanjing, China, pp. 263-268, July 28-30, 2014.

[13] M. Blanke, M. Kinnaert, J. Lunze and M. Staroswiecki, "Diagnosis and fault-tolerant control", Springer, Second Edition, Chapter 6, pp. 238263, 2006.

[14] M. Basseville and I. Nikiforov, "Detection of Abrupt Changes-Theory and Applications", Prentice-Hall, Englewood Cliffs, NJ., 1993.

[15] C. Delpha, D. Diallo, H. Al Samrout, N. Moubayed "Incipient fault detection and diagnosis in a three-phase electrical system using statistical signal processing", IEEE Industrial Electronics Conference (IECON 2017), Oct. 29-Nov 1, Beijing, China, pp. 3828-3833, 2017. 
